DOI 10.37882/2500-3682.2020.10.13

\title{
ИССЛЕДОВАНИЕ КРЕАТИВНОСТИ КАК КОМПОНЕНТА ПСИХОЛОГИЧЕСКОЙ ГОТОВНОСТИ СТУДЕНТОВ ДЕФЕКТОЛОГИЧЕСКИХ СПЕЦИАЛЬНОСТЕЙ К РАБОТЕ в УСЛОВИЯХ ИНКЛЮЗИИ
}

\section{RESEARCH OF CREATIVITY AS A COMPONENT OF PSYCHOLOGICAL READINESS OF STUDENTS OF DEFECTOLOGICAL SPECIALTIES TO WORK IN CONDITIONS OF INCLUSION}

\section{O. Nazarevich}

Summary: The modern system of education in Russia involves the inclusion of children with disabilities in the General education process. Currently, there is a sufficient number of research works devoted to the study of the problems of inclusive education, one of which is the problem of special training of teachers to work in an inclusive environment. Research on the components of psychological readiness of teachers and future specialists to work in an inclusive practice has become particularly relevant.

In research of psychological readiness, the specific content of each component is not sufficiently studied, but there are some research works which consider the characteristics of the teacher's or specialist's personality, which are necessary for work with children with disabilities, including the conditions of inclusion. As the main aspect of our research we consider the concept of personal readiness of the future specialists of defectological profile for work in an inclusive practice.

As one of the components of this type of readiness, we study creativity, since a teacher of inclusive education who works in a modern school must be able to find original solutions to problems and tasks, be able to look at the standard situation in a new way, be able to overcome the stereotype of behavior, create a unique and original product of their own activities. This article considers the issues of research of personal creativity of future specialists of defectological specialties based on the use of diagnostics of personal creativity. There the results of theoretical and applied research of the parameters of personal creativity of students, their age dynamics are presented.

The author describes the main directions of work on the development of creativity as a component of the psychological readiness of future defectologists to work in modern inclusive education.

Keywords: inclusive education, inclusion, psychological availability for service in the conditions of inclusion, components of psychological availability, creativity.

\section{Постановка проблемы}

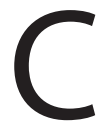

овременную систему образования в России уже невозможно представить без инклюзивного обучения детей с ОВ3 в условиях общеобразовательных

\author{
Назаревич Оксана Сергеевна \\ К.nсх.н., доцент, ФГБОУ ВО «Шадринский \\ государственный педагогический университет» \\ osn24@mail.ru
}

Аннотация: Современная система образования в России предполагает включение детей с ограниченными возможностями в общеобразовательный процесс. В настоящее время появилось достаточное количество исследований, посвященных изучению проблем инклюзивного образования, одной из которых является проблема специальной подготовки педагогов к работе в условиях инклюзии. Особенно актуальными стали исследования компонентов психологической готовности педагогов и будущих специалистов к работе в условиях инклюзивной практики.

В исследованиях психологической готовности недостаточно исследовано конкретное содержания каждой составляющий, но есть работы, в которых рассматриваются особенности личности педагога или узкого специалиста, необходимые для работы с детьми с ОВЗ, В том числе в условиях инклюзии. В рамках нашего исследования как основное мы рассматриваем понятие личностной готовности будущих специалистов дефектологического профиля к работе в условиях инклюзивной практики. В качестве одного из компонентов данного вида готовности мы исследуем креативность, так как педагог системы инклюзивного образования, работающий в современной школе, должен уметь находить оригинальные решения проблем и задач, уметь посмотреть на стандартную ситуацию по-новому, уметь преодолеть стереотип поведения, создавать уникальный и оригинальный продукт собственной деятельности.

В данной статье рассматриваются вопросы исследования личностной креативности будущих специалистов дефектологических специальностей на основе использования диагностики личностной креативности. Представлены результаты теоретико-прикладного исследования параметров личностной креативности студентов, их возрастная динамика.

Автором описаны основные направления работы по развитию креативности как компонента психологической готовности будущих дефектологов к работе в условиях современного инклюзивного образования.

Ключевые слова: инклюзивное образование, инклюзия, психологическая готовность к работе в условиях инклюзии, компоненты психологической готовности, креативность.

учреждений. В настоящее время появилось достаточное количество исследований, посвященных изучению проблем инклюзивного образования. Исследованием проблемы специальной подготовки педагогов к работе в условиях инклюзии посвящены работы И.В. Гурьяновой 
[8], О.С. Кузьминой [10], С.В. Лауткиной [11], Е.В. Шипиловой [17]. Особенно актуальными стали исследования компонентов психологической готовности педагогов и будущих специалистов к работе в условиях инклюзивной практики.

С.А. Черкасова в своем исследовании выделяет психологическое, акмеологическое, психолого-педагогическое, педагогическое направления в исследовании готовности к профессиональной деятельности и личностная, функциональная, личностно-деятельностная плоскости [16].

С.В. Алехина, М.А. Алексеева, Е.Л. Агафонова, Л.П. Фальковская рассматривают готовность педагогов к работе в условиях инклюзивного образования через два основных показателя: профессиональная готовность и психологическая готовность $[1,2,3]$.

Д.В. Воробъева определяет психологическую готовность как совокупность внутренних и внешних условий, к которым в том числе относятся личностные качества специалиста-педагога: интеллеклтуальные, мотивационные, эмоционально-волевые, профессионально-ценностные, обеспечивающие готовность к профессиональной деятельности [6].

Мы, рассматривая понятие личностной готовности, опираемся на работы О.Ф. Богатой [5], Е.В. Гребенниковой и Е.Ю Закотновой [7] и понимаем его как проявление индивидуально-личностных качеств, необходимых для осуществления будущей профессиональной деятельности.

В качестве одного качеств личности педагога, осуществляющего инклюзивную практику, мы рассматриваем креативность. В специальной литературе креативность рассматривается как суммарная характеристика личности, под которой подразумевается способность создавать новое, оригинальное.

Е.В. Кетриш отмечает, что у педагогов системы инклюзивного образования, работающих в современной школе, возникает задача формирования умения находить оригинальные решения проблем и задач, уметь посмотреть на стандартную ситуацию по-новому, уметь преодолеть стереотип поведения, создавать уникальный и оригинальный продукт собственной деятельности [9].

И.Л. Федотенко в своей работе выделяет креативность как личностный компонент компетентности педагога [13]. И.М. Яковлева включает креативность и творческий подход к решению проблем и задач в структуру профессионально-личностной готовности к работе с детьми с ОВ3 [19] . Ю.В. Шумиловская рассматривает креативность как один из компонентов в структуре готовности к работе в условиях инклюзивного образования у будущих педагогов [18]. Е.В. Шипилова направленность на развитие творческого потенциала личности студента считает одним из системообразующих факторов готовности к профессиональной деятельности [17].

Следует отметить, что исследователи в основном только упоминают о необходимости формирования креативности как компонента готовности педагогов к работе в условиях инклюзивной практики, вопросы исследования компонентов креативности в структуре готовности педагогических работников к работе в условиях инклюзивного образования рассматриваются крайне мало, это и обусловило актуальность нашего исследования.

Целью данного исследования является изучение содержания, возрастной динамики и гендерных различий показателей креативности студентов дефектологических специальностей педагогического университета.

\section{Анализ исследований}

В специальной литературе нет единой точки зрения на определение креативности. Большая часть исследователей данного феномена сходятся во мнении, что термин креативность имеет два смысловых варианта: собственно творчество и творческая деятельность конкретной личности. По мнению Е.Е. Подгузовой определение креативности базируется на предметных областях, в качестве которых выделяют: креативное мышление и связанные с ним познавательные процессы, креативное поведение, внешние креативные продукты, креативную среду, креативную личность [12].

В нашем исследовании мы опирались на определение Т.А. Барышевой и рассматривали креативность как «творческую стилистику поведения, обеспечивают продуктивность, новизну, уникальность способов и результатов деятельности, предрасположенность и готовность личности к творческим преобразованиям в различных сферах жизнедеятельности» [4,с. 56].

Анализ литературы по проблеме исследования показал, что исследователи разграничивают понятия креативности и творчества, определяют специфические особенности параметров креативности, изучают возрастные аспекты данного явления, выявляют признаки креативности. Мы акцентировали свое внимание на исследовании параметров личностной креативности (любознательность, воображение, предпочтение сложных идей и склонность к риску) и продуктивных показате- 
лей креативности (оригинальность, разработанность, беглость, гибкость) с целью дальнейшего определения готовности испытуемых к работе в условиях инклюзии.

Для исследования параметров креативности испытуемых мы использовали методику «Диагностика личностной креативности» Е.Е. Туник [15] и тест креативности Э.Торренса [14].

\section{Изложение основного материала исследования}

Теоретико-прикладное исследование осуществлялось на базе ФБГОУ ВО «Шадринский государственный педагогический университет». В качестве испытуемых выступили 52 студента факультета коррекционной педагогики и психологии, обучающихся по направлению подготовки 44.03.03 Специальное (дефектологическое) образование (профиль - Специальная психология; Логопедия). В экспериментальном исследовании участвовали студенты обоего пола, возраст испытуемых - от 18 до 24 лет. В исследовании приняли участие бакалавры первого, второго и третьего курсов и магистранты первого года обучения.

Анализ результатов исследования показателей личностной креативности показал, что наиболее выраженной характеристикой у испытуемых стала любознательность (средний балл по данному параметру по всей выборке составил 56,5), на втором месте - склонность к риску (средний балл - 55,1), на третьем месте - сложность решаемых задач $(50,4)$. Менее выраженной характеристикой по всей выборке испытуемых стало воображение (средний балл - 38).

Мы не вывили значимые гендерные различия в проявлении исследуемых параметров, хотя предполагали, что у студентов мужского пола будет в большей степени проявляться склонность к риску и они будут выбирать более сложные пути решения проблем.

Высокий уровень развития любознательности характерен для 61, 5 \% студентов первого курса, для 33,3 \% студентов второго курса, 26, 7 \% третьего курса. Нами не вывялено ни одного магистранта с высоким уровнем развития любознательности. Для испытуемых с высоким уровнем любознательности характерны следующие особенности: они пытаются найти новые пути решения проблем или новые способы мышления, активно изучают новые идеи, интересуются достаточно широким кругом проблем.

Количество студентов со средним уровнем любознательности увеличилось с 38,5 \% у первокурсников до $66,7 \%$ у студентов второго и третьего курса, а у ма- гистрантов уменьшилось до 50\%. Для этих испытуемых описанные выше характерные особенности представлены в меньшей степени.

Нами не выявлено испытуемых с низким уровнем любознательности у студентов первого и второго года обучения, количество третьекурсников с низким уровнем составило 6, 7\%. Для 50\% магистрантов характерен низкий уровень любознательности.

Эти данные свидетельствуют о том, что с возрастом снижается интерес к большому кругу событий и явлений, человек меньше интересуется новыми идеями. Частично мы объясняем это тем, что с повышением уровня профессиональной подготовки студенты акцентируют интерес на отдельной проблематике, в рамках которой проводят свою учебно-исследовательскую деятельность.

Еще один анализируемый параметр - склонность к риску. К высокому уровню нами отнесено примерно одинаковое количество студентов - бакалавров: $38,3 \%$ испытуемых первого курса, 44,4\% - второкурсников, 33,3\% - третьекурсников. Количество магистрантов с высоким уровнем склонности к риску составило 50\%.

По мнению Е.Е. Туник люди с высоким уровнем развития данного параметра предпочитают рисковать, они отстаивают свои идеи, не обращая внимание на мнение окружающих или устоявшиеся точки зрения, допускают возможность ошибок и провалов, не склонны поддаваться чужому влиянию. Мы считаем, что для работы в условиях большого количества проблем в системе инклюзивного образования эти особенности имеют положительную направленность, однако следует обратить внимание на развитие умения целостно оценивать картину или явление, формировать критичность мышления у студентов с высоким уровнем склонности к риску.

Не значимо различается количество испытуемых со средним уровнем склонности к риску: на первом курсе $57,7 \%$, на втором - 55,6 \%, на третьем - 6,7, у магистрантов $-50 \%$.

Только 3,8\% всех обследованных отнесены нами к низкому уровню, это студенты первого курса. Эти данные, по-нашему мнению, обусловлены возрастными особенностями испытуемых, поскольку молодые люди в большей степени склонны к риску, чем более возрастные. Кроме того, мы не подтвердили нашу гипотезу о более выраженной склонности к риску у юношей, студенты обоего пола набирали максимально высокие баллы при оценке данного параметра. 
Следующий параметр, который мы оценивали сложность. Примерно одна десятая часть бакалавров имеет высокий уровень проявления данного параметра. Эти студенты характеризуются проявлением интереса сложным идеям и вещам, ставят перед собой трудные задачи, проявляют настойчивость в решении проблемы, однако они предлагают слишком сложные пути ее решения и стараются избегать посторонней помощи. В условиях работы в системе инклюзивного образования такая практика может привести к эмоциональному выгоранию и потере интереса к профессиональной деятельности.

Основная часть испытуемых имеет средний уровень выраженности данного параметра - примерно 80\% студентов-бакалавров. У магистров эта цифра достигает 100\%. Низкий уровень имеют 3,8\% первокурсников и $11.1 \%$ студентов второго курса.

Менее выраженным параметром личностной креативности, по результатам проведенного исследования, стал параметр воображения. К высокому уровню мы отнесли 3,8 \% студентов первого года обучения и 20\% третьекурсников. Эти испытуемые видят предметы и явления в необычном ракурсе, умеют фантазировать. Но склонность к фантазиям не всегда может помогать продуктивно решать задачи инклюзивного образования.

Средний уровень воображения характерен для 61,5\% обучающихся первого курса, 88,9\% - второго и 73,3 \% - третьего курса, 50\% магистрантов.

Низкий уровень развития воображения наиболее характерен для студентов первого курса (34,6\%), а также для магистрантов (50\%). 11,1 \% студентов второго курса и 6,6 \% третьего курса имеют низкий уровень воображения.

Исследование продуктивных компонентов креативности испытуемых показало, что достаточно наиболее развиты такие показатели вербальной креативности, как беглость и гибкость, проявление оригинальности находится на невысоком уровне. Результаты исследования образной креативности свидетельствуют о том, что наиболее выраженными являются параметры беглости, гибкости и оригинальности, а разработанность образов развита недостаточно. С возрастом у студентов уменьшается количество образов за счет увеличения их разработанности.

Дальнейшая работа по формированию показателей креативности как компонента готовности студентов к работе в условиях инклюзии предполагает разработку системы специально организованных занятий, направленных на формирование у будущих специалистов не только готовности к восприятию нового, но и развитие умения действовать по-новому, осуществлять творческий подход к решению проблем инклюзивного образования.

Разработанная нами программа предполагает осуществление работы в форме психологического кружка. Каждое занятие состоит из теоретической и практической части. Теоретическая часть включала в себя получение студентами информации о специфике и содержании инклюзивного образования и процессов сопровождения ребенка с ОВ3 в условиях общеразвивающего учреждения, практическая часть предполагала включение разнообразных методов непосредственной работы студентов по получению и закреплению навыков работы с детьми с ОВ3, в том числе задания и упражнения на развитие креативности.

\section{Выводы}

Проведенное нами экспериментальное исследование свидетельствует о том, что студенты за короткий отрезок времени генерируют большое количество идей, они способны применять различные подходы к решению задач, но в большей степени созданные образы и подходы формальны, не отличаются оригинальностью. К старшим курсам у студентов появляется больше абстрактных понятий, они начинают более тщательно прорабатывать образы.

Нами не выявлены значимые гендерные различия в проявлении креативности у студентов, но выявлены возрастные изменения: к старшим курсам снижается любознательность и проявление творческого воображения, увеличивается склонность к риску и сложность создаваемых образов.

Для развития креативности как компонента личностной готовности к работе в условиях инклюзии необходимо: повышение уровня развития любознательности, регулировка степени выраженности стремления выбирать наиболее сложные способы действия и мышления, развитие воображения, умения целостно оценивать картину или явление, формирование критичности мышления, развитие оригинальности и разработанности образов, однако эти изменения не очень выражены.

Мы предполагаем, что реализация программы развития параметров креативности поможет сформировать у студентов определенные личностные качества, которые будут способствовать более успешному включению будущих специалистов в практику инклюзивного образования. 


\section{ЛИТЕРАТУРА}

1. Алёхина С.В., Фальковская Л.П. Педагог инклюзивной школы: новый тип профессионализма // М.: Педагогический университет, «Первое сентября», 2014. $-28 \mathrm{C}$.

2. Алёхина С.В. Подготовка педагогических кадров для инклюзивного образования // Педагогический журнал. - 2013. - № 1 (44). - С. 26 -32.

3. Алехина С.В., Алексеева М.Н., Агафонова Е.Л. Готовность педагогов как основной фактор успешности инклюзивного процесса в образовании // Психологическая наука и образование. - 2011. - №1. - С. 83-91.

4. Барышева, Т.А. Психологическая структура креативности // Известия РГПУ им. А.И. Герцена. - № 142. - 2012. - С. 54-64

5. Богатая 0.Ф. Профессиональная и психологическая готовность педагогов как условие реализации инклюзивного образования // Наука, образование, общество: тенденции и перспективы развития : материалы Междунар. науч.-практ. конф. — Чебоксары: ЦНС «Интерактив плюс», 2015. — С. 78-85.

6. Воробьева Д.В. Понятие психологической и профессиональной готовности педагогов к работе с детьми с ОВЗ в инклюзивной практике // Личность, семья и общество: вопросы педагогики и психологии: сб. ст. по матер. Х междунар. науч.-практ. конф. - Новосибирск: СибАК, 2011.- С. 68 - 75.

7. Гребенникова Е.В., Закотнова Е.Ю. Психологическая готовность студентов-психологов к профессиональной деятельности в условиях инклюзивного образования // Вестник ТГПУ.- 2015. - № 3 (156). - С.34-37.

8. Гурьянова И.В. О методах и критериях подготовки социальных педагогов к работе в инклюзивной образовательной среде // Инклюзивное образование: теория и практика: сб. материалов междунар. науч.-практ. конф.- Орехово-Зуево: Редакционно-издательский отдел ГГту. - 2016. - С.828-834.

9. Кетриш Е.В. Готовность педагога к работе в условиях инклюзивного образования : монография / Е.В. Кетриш ; [рец.: Е.А. Югова, Н.В. Третьякова] ; Рос. гос. проф.-пед. ун-т. — Екатеринбург: Издательство РГППУ, 2018. — 120 с.

10. Кузьмина 0.С. Проблемы подготовки педагогов к работе в условиях инклюзивного образования // Педагогические науки, 2016. -№ 4. - С.34- 45.

11. Лауткина С.В. Профессиональная готовность будущих педагогов к работе в условиях инклюзивного образования // Инклюзивное образование: проблемы и перспективы: сб. науч. трудов междунар. науч.-практ. конф. «Сетевое взаимодействие университетов с социальными партнерами в области инклюзивного образования: международный и региональный аспект» - Великий Новгород:, 2014. - С.142-149.

12. Подгузова Е.Е. Креативность личности: возможности развития в условиях вуза: монография. - Смоленск, СГИИ, 2001. 119с.

13. Федотенко И.Л., Проблемы социальной профессионально-личностной адаптации начинающего учителя — Тула: Изд-во Тул. гос. пед. ун-та им. Л. Н. Толстого, 2006. - 73 c.

14. Туник Е.Е. Диагностика креативности. Тест Е. Торренса. Спб.: Иматон, 1998. - 158 с.

15. Туник Е.Е. Диагностика личностной креативности / Фетискин Н.П., Козлов В.В., Мануйлов Г.М., Социально-психологическая диагностика развития личности и малых групп. - М, 2002. - - 59-64.

16. Черкасова С.А. Система подготовки будущих педагогов-психологов к работе в условиях инклюзивного образования // Инклюзивное образование: методология, практика, технологии: Материалы междунар. науч.-практ. конф. - М.: МГППУ. - 2011. - С. 221-223.

17. Шипилова Е.В. Подготовка будущих педагогов-дефектологов к проектированию и реализации коррекционно-развивающего процесса / Е.В. Шипилова // Актуальные проблемы образования: история и современность: сб. ст. междунар. науч.-практич. Конф. - Волгоград: Изд-Во ВолГУ. - 2012. - С. 183-189.

18. Шумиловская, Ю.В. Подготовка будущего учителя к работе с учащимися в условиях инклюзивного образования: автореф. ... канд. пед. наук: 13.00 .08 / Ю.В. Шумиловская [Электронный ресурс]. - Режим доступа: sspu.ru/pages/postgraduate/doc/abstracts/2011/shumilovskaya.doc. - Дата доступа: 06.09.2020.

19. Яковлева И.М. Профессионально-личностная готовность педагога к работе с детьми с ограниченными возможностями здоровья //Вестник МГопу. Серия «Педагогика». - 2009. - № 6. - С. 140-144.

() Назаревич Оксана Сергеевна (osn24@mail.ru). 